\title{
An indoor pelagic mesocosm facility to simulate multiple water-column characteristics
}

\author{
Ulf Båmstedt $[$ • Henrik Larsson
}

Received: 12 July 2017 / Accepted: 13 December 2017/Published online: 8 January 2018

(C) The Author(s) 2018. This article is an open access publication

\begin{abstract}
Mesocosms are important research tools in aquatic ecology because they close the gap between laboratory studies at the individual or lower organization level and field studies at the population and ecosystem level. However, most mesocosm studies regarding the pelagic environment do not consider the effects of physical factors like water-column stratification, turbulence and mixing. Neglecting such factors might bias the results compared to the natural system. Using a unique indoor mesocosm facility, we present results on how different water-column stratifications can be made and how they act as barriers for exchange between water layers. Turbulent mixing, simulated by vertically rotating incubation vessels, is shown to be of high importance for primary production, generating up to nine times higher production in humus-rich water than incubation vessels at fixed depths. Convective stirring is shown to be an attractive method for generating different turbulence conditions, and different temperature settings can be used to get turnover times from $84 \mathrm{~h}$ or more down to $17 \mathrm{~min}$ for a $5-\mathrm{m}$ water parcel. We also demonstrate how an anoxic bottom layer can be achieved by stimulating heterotrophic bacteria through addition of bioavailable organic carbon.
\end{abstract}

Keywords Aquatic mesocosms - Turbulent mixing · Primary production · Pycnocline strength $\cdot$ Light spectrum $\cdot$ Bacterial oxygen depletion $\cdot$ Thermal convection

\section{Introduction}

Mesocosm-based research has become an increasingly important part of aquatic ecology by closing the gap between laboratory studies at the species, individual or lower organisation level and field studies at the population or ecosystem level (Stewart et al. 2013). Field studies in the marine environment often require large research ships with daily costs of $10,000 €$ or more and studies on natural systems, especially pelagic ones, also include much short-term variability. Thus, high cost of marine field studies combined with the inherent natural spatial and temporal variability heavily constrains the possibility of achieving statistically well-founded results solely based on field studies. Alternately, laboratory studies at the individual level can, for example, precisely define physiological responses to both abiotic (light, temperature, salinity, etc.) and biotic variables (food concentration and quality, crowding, gender, age, etc.). However, the complexity in the natural environment is not fully reflected in the relatively small volume of water used in laboratory experiments, and the time scales used are usually short. For example, Miko et al. (2015) compared results from ecotoxity tests on tadpoles in the lab and in outdoor mesocos which showed strikingly different results.

U. Båmstedt $(\bowtie) \cdot$ H. Larsson

Umeå Marine Sciences Centre, University of Umeå, Norrbyn, 90571 Hörnefors, Sweden

e-mail: ulf.bamstedt@umu.se 
However, due to the reduction in complexity also present in a mesocosm, extrapolation of results from mesocosms to the natural environment should be done with caution. Spivak et al. (2011) concluded that results from mesocosm-scale experiments on micro-algae probably are relevant to large-scale processes, such as eutrophication. On the other hand, Williams et al. (2002) found that freshwater pond mesocosms showed lower biodiversity than corresponding natural ponds. Mesocosms in a mesotrophic and a eutrophic lake showed the same water chemistry as the surrounding water, but most biological variables diverged from the surrounding water (Dzialowski et al. 2014). The tendency of diverging succession in mesocos and natural habitats has been repeatedly shown by Schindler and colleagues (see, e.g., Schindler 1998 for a review). Another problem is variability between replicate mesocosms. Caquet et al. (2001) showed that water temperature, $\mathrm{pH}$, dissolved oxygen and suspended solids exhibited a very low variability between replicate mesocosms whereas nutrients displayed elevated variability. They also found that biological parameters at the individual level were less variable than those at the community level.

Table 1 represents an attempt to categorize and compare different types of mesocosms and also compare with open field studies, thus giving a rough overview of which type of basic tool should be the best choice for a given research question. Costs, working conditions, range of environmental manipulation and measurement possibilities and replication possibilities have been considered. To cover as much as possible of the volume and depth ranges, the natural environment is of course number one, and going from sea/lake-based to landbased and indoor mesocosms gradually reduces the possible range in volume and depth. Field studies are also best if natural light conditions and irradiance profiles are of primary importance, although sea/lake-based mesocosms can provide the same light conditions as in nature; they have a practical limit in depth and thereby also a more restricted range in the vertical irradiance profile.

Sea-based mesocosms might yield more potential to use many replicates than land and indoor facilities, and therefore a better statistical evaluation of the results. Sea/lake-based mesocosms are often inexpensive, at least compared to the indoor variant, and provide better opportunities for a natural light environment. The negative characteristics of sea/lake-based mesocosms compared to land and indoor facilities are their sensitivity to weather conditions and very restricted potential to control light, temperature and turbulent mixing, whereas the ability to adjust nutrients, $\mathrm{pH}$ and food-web structure is approximately the same as for the land-based and indoor counterparts.

Table 1 Relative suitability of the basic research tool for doing ecological studies in pelagic environments

\begin{tabular}{|c|c|c|c|c|}
\hline Function & A & B & $\mathrm{C}$ & $\mathrm{D}$ \\
\hline Choice of volume & $* * * * *$ & $* * *$ & ** & * \\
\hline Choice of depth range & $* * * * *$ & $* * * *$ & ** & $*$ \\
\hline Sensitivity to weather conditions & $* * *$ & $*$ & $* * * *$ & $* * * * *$ \\
\hline Access and working conditions & $* * *$ & $* *$ & $* * * *$ & $* * * * *$ \\
\hline Statistically based investigations & $* *$ & $* * * * *$ & $* * * *$ & $* * * *$ \\
\hline Sensor-based online monitoring & $*$ & $* *$ & $* * * * *$ & $* * * * *$ \\
\hline Cost of a comparable research study & $* *$ & $* *$ & $* * * *$ & $* * * * *$ \\
\hline Use of natural light conditions & $* * * * *$ & $* * * * *$ & $* * * *$ & $* * *$ \\
\hline Adjustment of light conditions & - & $*$ & $* * *$ & $* * * * *$ \\
\hline Range in vertical irradiance profile & $* * * * *$ & $* * *$ & $* * * *$ & $* * * *$ \\
\hline Adjustment of nutrient conditions & $*$ & $* * * *$ & $* * * * *$ & $* * * * *$ \\
\hline Adjustment of temperature conditions & - & $*$ & $* * *$ & $* * * * *$ \\
\hline Adjustment of salinity conditions & - & $* *$ & $* * * * *$ & $* * * * *$ \\
\hline Adjustment of $\mathrm{pH}$ conditions & - & $* * * *$ & $* * * * *$ & $* * * * *$ \\
\hline Control of turbulent mixing & - & $*$ & $* * *$ & $* * * * *$ \\
\hline Density stratification of water parcel & $*$ & $* *$ & $* * *$ & $* * * * *$ \\
\hline Manipulation of food-web structure & $*$ & $* * * * *$ & $* * * * *$ & $* * * * *$ \\
\hline
\end{tabular}

$\mathrm{A}=$ Ship-based studies in the field; $\mathrm{B}=$ Sea-based mesocosms; $\mathrm{C}=$ Land-based mesocosms; $\mathrm{D}=$ Indoor mesocosms. The relative suitability scale goes from - , meaning not possible to $* * * * *$, meaning highly suitable 
Land-based and indoor mesocosms have a number of advantages, such as easy access, good working conditions, very low sensitivity to weather conditions, best possibilities for sensor-based online monitoring and especially that indoor mesocosms provide the best opportunity for manipulation of the physical environment. The number of land or indoor mesocosm units is usually restricted due to restricted space, and the number of replicate treatments and treatment levels will, therefore, also be restricted. Cost is an important factor in the choice of research tool, and land-based and indoor mesocosms often have a high initial construction cost but require limited operation budgets thereafter. A ship-based field study has full costs every time, and sea/lake-based mesocosm facilities often require frequent repair and renewal of parts.

A range of physical, chemical and biological shortcomings are obvious when trying to extrapolate mesocosm results to natural ecosystems (Schindler 1998). An enclosure of a water mass will inevitably differ in some conditions from the natural ones, and one factor that has received attention is the importance of dimensional relationships of the actual enclosure. Mesocosms with the same volume but different dimensional properties will often generate different results (e.g., Petersen et al. 1999; Petersen and Englund 2005). This might be explained by, for example, a changed surface/volume ratio or changes in the light environment and in air-water exchange processes. An obvious effect of an increased surface to volume ratio is a potential for build-up of periphyton biomass on the inside walls, which will act as an increasingly important factor for the flow of energy and material in the mesocosm during the time span of a study.

Most ecological studies using mesocosms lack information on physical characteristics of the experimental environment. Factors like mixing, turbulence, light spectrum and exchange rate through discontinuity layers are very important for biological processes and, if different from the natural environment, may cause biased results as compared to the natural environment. The natural environment in the sea and lakes is usually also stratified during most of the year, although thermoclines or pycnoclines are seldom part of a mesocosm-based ecological study. In this paper, we describe a unique mesocosm facility where the physical characteristics can be controlled and manipulated and give some examples of biological consequences of different physical conditions.

\section{Materials and methods}

For our functional tests and experimental evaluations, we used the indoor mesocosm facility at Umeå Marine Sciences Centre, University of Umeå, Sweden, situated at the northern Bothnian Sea (N63 $34^{\prime}$; E1 $\left.19^{\circ} 50^{\prime}\right)$ in the Baltic Sea.

\section{The experimental facility}

The facility is located in a 6-m-high temperature-regulated hall with a second floor about $120 \mathrm{~cm}$ below the top of the mesocosms, with a laboratory in direct connection to this upper floor (Fig. 1a). It consists of 12 insulated black cylindrical polyethylene tanks, $5 \mathrm{~m}$ high with an inner diameter of $0.73 \mathrm{~m}$. There are three 1.4$\mathrm{m}$-high vertical sections in each mesocosm where the temperature is monitored and regulated (Fig. 1a), separated by two $0.4-\mathrm{m}$-high sections. The wall of each $1.4-\mathrm{m}$ unit is divided into six interconnected concentric sections with holes in the dividing lamellae on opposite sides of two neighbouring sections (Fig. 1b), and with an inlet for the temperature control medium at the bottom and an outlet at the top section. The temperature control medium (40\% propylene glycol, Dowcal 20) is, thus, forced to circulate around the wall (Fig. 1b). The outer part of the wall comprises an air-filled section that insulates the entire mesocosm tank (Fig. 1b). The actual temperature-control system consists of two units for circulation of the glycol solution, one with cold $\left(-6^{\circ} \mathrm{C}\right)$ and one with warm $\left(30^{\circ} \mathrm{C}\right)$ solution. Both are connected to each of the three vertical sections on each tank (Fig. 1b) through computer-controlled valves that direct either cold or warm glycol solution according to the desired temperature (Honeywell AB, Johanneshov, Sweden and Gate AB, Umeå, Sweden). In general, the maximum deviation from the desired temperature is within $\pm 0.5^{\circ} \mathrm{C}$. The two intermediate sections of $0.4 \mathrm{~m}$ in height can either be switched off or connected in parallel with an adjacent 1.4-m temperature control section.

The technical design described above makes it possible to set up stratified water columns with a thermocline at $1.5-2 \mathrm{~m}$ in depth, at 3.2-3.7 $\mathrm{m}$ in depth, or at both depths. The temperature control system can also 
a Tank dimensions

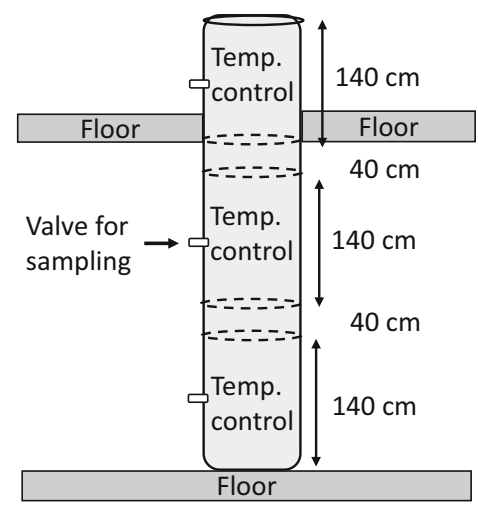

b Wall construction

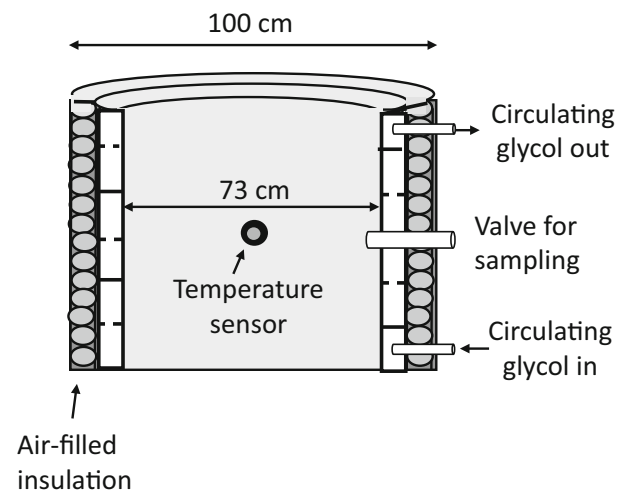

Fig. 1 Simplified view of a mesocosm tank. a Dimensions of the entire tank showing the positions of the three sections with temperature control and the two smaller sections between them. b Cross-view of the tank wall in one temperature-controlled section

be used to create convective stirring at different rates. A slight increase in the temperature settings in one or both of the two lower sections promotes convective stirring in the water column. It is also possible to maintain convective stirring above a cooler bottom layer by a similar slight offset in the temperature settings between the middle and upper sections. Faster convective stirring can also be maintained by maximum heating at the low section and maximum cooling at the top section, thus allowing the middle section to control the overall temperature in the water column. Further increase in pycnocline strength can be achieved by dissolving sea salt in the water. Each mesocosm tank is irradiated by an HID metal halogen lamp (Philips MH/CDM-T $150 \mathrm{~W} / 930$ ) with an emission spectrum resembling that of natural sunlight but with lower irradiance than sunlight below $400 \mathrm{~nm}$. The position of the lamp in our experiments was adjusted to give $400 \mu \mathrm{mol}$ quanta $\mathrm{m}^{-2} \mathrm{~s}^{-1}$ immediately below the water surface in all mesocosm tanks.

The mesocosm facility also includes an automatic system for water exchange, where a given percentage of water renewal per time unit can be set. The tanks can be filled either from the ordinary water-supply system, with intake approximately $800 \mathrm{~m}$ offshore, from 2 to $8 \mathrm{~m}$ in depth, or through a second pipe system, where water directly from the dock outside the lab or from a transport truck can be used. Water from the ordinary water-supply system is normally passed through a 300- $\mu \mathrm{m}$ filter; it can also be pre-flushed with air, or it can be used without any pre-treatments. A valve system ensures that all tanks are filled in parallel. There is a movable filtering system with $10 \mu \mathrm{m}$ pre-filters (FSI Filter Spec. Int., Michigan City, Illinois, USA.) and patron filters down to $1 \mu \mathrm{m}$ (Roki Techno Co. Ltd, Tokyo, Japan) which can be connected to the system. It takes around $3 \mathrm{~h}$ to fill all tanks without filtering and around $16 \mathrm{~h}$ to fill them with $1-\mu \mathrm{m}$-filtered sea water, including one necessary change of filters. A system is also available for collecting undisturbed bottom sediment from the field in shallow cylinders, fitted in size to the bottom of the mesocosm tanks. An automatic sampling device ensures reproducible sediment sampling over time (see Methods in Jonsson et al. 2014).

\section{Sampling}

For profiling of salinity, temperature, light (PAR, photosynthetic active radiation, 400-700 nm), oxygen saturation, chlorophyll a, turbidity and CDOM (colored dissolved organic matter), we used logging instruments, either an Aanderaa SeaGuard (see http://www.aanderaa.com) or Hanna HI 9828 multiparameter instrument with probe HI 769828 (see http://www.hannainst.com). The instrument was slowly lowered from the surface to the bottom with a measuring frequency of one per second (SeaGuard) or every $0.1-0.5 \mathrm{~m}$ in depth (Hanna). The chlorophyll- $a$ concentration was also measured after ethanol extraction of pigments from cells filtered on a Whatman GF/C filter, using a Perkin Elmer LS 30 Luminescence spectrometer (Aminot and Rey 2002). The light profiles in the mesocosms were used to calculate the light attenuation coefficients ( $k$ in 
the equation $I_{d}=I_{0} * e^{\left(-k^{*} d\right)}$, where $I_{d}$ is irradiance at $d$ meter depth, $I_{0}$ is irradiance at the surface, and $k$ is the slope in the exponential equation.

To study how materials on the inner walls with different optical properties influenced the light environment in the mesocosm tanks, we used thin glossy white PVC sheets (named White in the following) and thick aluminum foil (named Alu in the following) to cover the inside wall, in addition to the uncovered original black polyethene wall (named Black in the following). The mesocosm tanks were filled with tap water, the absolute irradiance was measured at $0.3,1,2,3,4$ and $4.4 \mathrm{~m}$ in depth, the water-column irradiance was calculated by trapezoid depth integration, and the results shown are relative to those for Alu. The light spectra were measured with Ocean Optics ${ }^{\mathrm{TM}}$ radiometers USB $2000+$ and USB 4000 (Ocean Optics, Winter Park, Florida, USA), with the fiber-optical cable mounted on a frame that held the tip of the fibre upward in a vertical position. To measure the highest irradiance levels, we used Teflon (polytetrafluoreten) tape as a neutral filter on the tip of the fibre. The instruments were calibrated using the Ocean Optics ${ }^{\mathrm{TM}}$ calibration unit, HAL 2000, before each series of measurements.

Water-column mixing and exchange through pycnoclines

The HID lamps emit heat that is transferred to the surface water. We recorded the temperature profiles in the water column with a temperature setting of $15^{\circ} \mathrm{C}$ in all three sections of the mesocosms and with different mixing methods. Temperature profiles were measured in undisturbed conditions, in water bubbled with compressed air from $60 \mathrm{~cm}$ in depth, in water with an undulating fan blowing air on the surface, and in water with a 200-W electrical heater placed at the bottom. A further study of the exchange rate of water between the heated surface and deeper layers was also performed with the undisturbed conditions and with the 200-W electrical heater placed at the bottom of the mesocosm. This was done by injecting a solution containing $4 \mathrm{~g}$ of humic acid (Aldrich pnr: 536080) at $2.4 \mathrm{~m}$ in depth and profiling the content of humic acid in the upper part of the water columns over time using a Turner Designs Cyclops-7 CDOM sensor (Turner Designs, San Jose, California, USA).

Air bubbling and fan blowing were also compared in a study of the mixing efficiency through a thermocline with a $5{ }^{\circ} \mathrm{C}$ temperature gradient. Air bubbling was done by lowering a PVC tubing with an outlet diameter of $18 \mathrm{~mm}$ to pre-defined depths and regulating the air pressure to give a bubbling frequency of one bubble per second. This bubbling strategy creates stirring but it does not aerate like an air diffuser since the area of the bubbles at any given time is negligible compared to the area of the water surface.

When testing air blowing on the surface, we arranged the fan to blow at $45^{\circ}$ towards the surface and undulate $45^{\circ}$ left and right. To promote convective stirring, we used either a submersible $250-\mathrm{W}$ heater or the three internal temperature control mantles that form parts of each mesocosm tank (Fig. 1). In these experiments, we used $160 \mathrm{mg}$ of rhodamine in $50 \mathrm{ml}$ of water, injected at $2.4 \mathrm{~m}$ in depth as described above.

Two different types of mixing rate experiments were performed. In one set of experiments, the rate of transport through thermoclines was studied. In another set of experiments, water-column mixing with different settings to promote convective stirring was studied. In both cases, we used a rhodamine solution that was slowly added through a small funnel with PVC tubing attached to the neck and with an air diffuser attached to the other end of the tubing. To ensure that all of the rhodamine was injected, the tubing was flushed with $100 \mathrm{ml}$ of water after the injection. The rhodamine solution and flush water was kept at the same temperature as the surrounding water. In the thermocline experiment, the temperature in the bottom layer was set to, respectively, 5,10 and $15{ }^{\circ} \mathrm{C}$, and to $20^{\circ} \mathrm{C}$ above this bottom layer in all three tanks. A rhodamine solution (160 mg in $50 \mathrm{ml}$ of water) was injected at $4.5 \mathrm{~m}$ in depth, and a $250-\mathrm{W}$ submersible heater was placed at $3.2 \mathrm{~m}$ in depth to ensure mixing in the upper water column. After adding the rhodamine, we lowered a small aquarium pump with horizontal in- and outlets down to the bottom and ran it for 1 min to get the bottom water well mixed with rhodamine. Vertical profiles of the rhodamine distribution were thereafter made over time, using a Turner Designs Databank handheld data logger with a pre-calibrated Turner Cyclops 7 model 2100-000 fluorimeter sensor (Turner Designs, San Jose, California, USA). After the profiling ended, the water column was mixed thoroughly, and the rhodamine concentration was recorded to get the equilibrium concentration. In the study of the transport rate through thermoclines, we divided the water column into four vertical sections, 0.2-1.8, 1.8-3.3, 3.3-3.6 $\mathrm{m}$ (main part of the thermocline), and 3.6-4.7 $\mathrm{m}$ (stagnant bottom layer where the rhodamine was added). The transport rate into the water above the bottom layer (above $3.6 \mathrm{~m}$ ) 
was calculated by normalizing the final equilibrium concentration of rhodamine to $100 \%$ and then plotting the $\%$ values of equilibrium rhodamine concentration over time and fitting a linear regression equation to the data. This is a simplification of the actual process since, in theory, a given proportion of water is mixed per time unit, which would generate a logarithmic succession. The exchange rate of rhodamine from the bottom layer through the thermocline was calculated by setting the start value minus the equilibrium value as $100 \%$, thereby normalizing the equilibrium rhodamine concentration to $0 \%$, and then plotting the $\%$ values over time. To define the effect of thermocline strength, i.e., the density difference between the bottom and overlaying water, we plotted the transport rate versus thermocline strength (density difference), both for transport into the upper two layers and out from the bottom layer, and adapted the best fit regression equation to the data.

In the studies of water-column mixing, we defined homogenous mixing as the time it takes for the concentration of rhodamine to stabilize to within $95-105 \%$ of the final equilibrium concentration. This was tested with three temperature conditions: (1) temperature settings of 14,15 and $16{ }^{\circ} \mathrm{C}$ in the low, middle and upper temperature-control sections, respectively, ensuring a continuous temperature increase from the bottom to the surface; (2) no temperature control, yielding a uniform temperature in the water column. (3) maximum heating in the low temperature-control section, a $15{ }^{\circ} \mathrm{C}$ setting in the middle section, and maximum cooling in the upper section, allowing for maximum convective stirring but with a constant temperature from the bottom to the surface. For these three experiments, we used $20 \mathrm{mg}$ of rhodamine in $10 \mathrm{ml}$ of water and injected it at $2.4 \mathrm{~m}$ in depth, followed by rinsing with $100 \mathrm{ml}$ of water and rhodamine profiling over time, as described above.

Primary production under different mixing conditions

Primary production was measured in two experiments. In one experiment, comparing rotating incubations with fixed-depths incubations, we used 120-min incubations and glass incubation vials of $20 \mathrm{ml}$ in volume, filled with water containing $40 \mathrm{mCi}$ of $\mathrm{Na}^{14} \mathrm{CO}_{3} 1^{-1}$. A series of five replicates was fixed to each of two submersed rotating rubber bands driven by an electrical motor, one band rotating from the surface to $1.5 \mathrm{~m}$ in depth, the other one from the surface to $4.5 \mathrm{~m}$ in depth, both with a speed of $0.97 \mathrm{~m} \mathrm{~min}^{-1}$. Duplicate vials were used for the rope incubations with positions at $0.2,0.4,0.6,1.0$ and $1.4 \mathrm{~m}$ in depth. After incubation, $5.0 \mathrm{ml}$ of the content was transferred to a pre-labelled plastic scintillation vial, $300 \mu \mathrm{l}$ of $3 \mathrm{M} \mathrm{HCl} \mathrm{was} \mathrm{added,}$ and the samples bubbled with air for $30 \mathrm{~min}$. A scintillation cocktail (Optiphase HiSafe 3, $15 \mathrm{ml}$ ) was thereafter added, and the content was mixed and measured in a Beckman 6500 scintillation counter, which gave the value for $\mathrm{DPM}_{\text {sample }}(\mathrm{DPM}=$ disintegrations per minute). For each experimental series, we prepared a standard series from the labelled water by pipetting out triplicates of 100, 200, 300 and $400 \mu l$ of the labelled water into $5 \mathrm{ml}$ of distilled water. Immediately thereafter, $15 \mathrm{ml}$ of scintillation cocktail was added, the content was mixed and measured as above. This gave the radioactivity in the incubation water, expressed as $\mathrm{DPM}_{\text {total }}$. The coefficient of variation of the average value was always less than $2 \%$ for all standard series. Carbon assimilation was then calculated from the formula below:

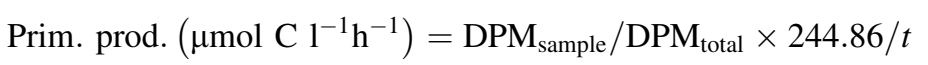

where $t$ is the incubation time in minutes and the constant 244.86 is a product of a factor of $1.10\left(\mathrm{sum} \mathrm{CO}_{2}\right)$, a factor of 1.05 for slower uptake of ${ }^{14} \mathrm{C}$ compared to ${ }^{12} \mathrm{C}$, a factor of 1.06 for correction of respiration loss during incubation, and a factor of 200 for conversion from production in $5 \mathrm{ml}$ to 11 . See Colijn and Edler (1998) for further description.

Primary production per $\mathrm{m}^{2}$ and hour for rotating incubations was obtained as the calculated primary production per $\mathrm{m}^{3}$ and hour times the rotating depth (i.e., 1.5 or $4.5 \mathrm{~m}$ ). Primary production per $\mathrm{m}^{2}$ and hour for the rope incubations was given by first calculating the exponential regression equation of primary production $\mathrm{m}^{-3} \mathrm{~h}^{-1}$ versus depth and then integrating over $0-1.5 \mathrm{~m}$, respectively, for $0-4.5 \mathrm{~m}$ in depth. The experiments were done with unfiltered brackish water containing added nutrients in surplus and with brackish water containing either 4 or $8 \mathrm{mg}^{-1}$ of dissolved humic acid (Aldrich pnr: 536080) in addition to the nutrients. In the second experiment, where we studied oxygen succession in a carbon-enriched environment, primary production was determined using 3-h incubations at mid-day with $100 \mathrm{ml}$ of water in Nunc culture 
bottles to which $3.2 \mu \mathrm{Ci}$ of $\mathrm{Na}^{14} \mathrm{CO}_{3}$ where added. We used a light:dark cycle of $16: 8$. Single bottles were incubated at $0.1,0.2,0.4,0.6,0.8,1.2,1.6$ and $2.0 \mathrm{~m}$ in depth. A pycnocline at $3-3.5 \mathrm{~m}$ in depth separated the upper mixed water parcel $\left(18{ }^{\circ} \mathrm{C}, 4.41 \mathrm{~g} \mathrm{~kg}^{-1}\right.$ salinity) from the bottom layer $\left(10^{\circ} \mathrm{C}, 5.07 \mathrm{~g} \mathrm{~kg}^{-1}\right.$ salinity). An airlift system consisting of a 5-cm-wide pipe with its lower end at $3.2 \mathrm{~m}$ in depth, its upper end at the surface and tubing that delivered air bubbles into the lower end of the pipe ensured continuous mixing of the water above the pycnocline.

Further laboratory procedures and calculation of primary production per $\mathrm{m}^{2}$ was done as defined for rope incubation above. Conversion to production per day from production per hour was done by multiplying by 16 (the daily light period).

Oxygen depletion and bacterial production

Bacterial production was measured in the oxygen succession experiment. We used 1-h incubations at in situ temperature with ${ }^{3} \mathrm{H}$-labeled thymidine $\left(\right.$ Amersham ${ }^{\circledR}, 1 \mathrm{mCi} \mathrm{ml}^{-1}, 80 \mathrm{Ci} \mathrm{mmol}^{-1}$ ) at a final concentration of $25 \mathrm{nM}$ using a conversion factor of $1.4 \times 10^{18} \mathrm{cells} \mathrm{mol}^{-1}$ (Wikner and Hagström 1999). Triplicate incubations and two controls (cold TCA added to 5\% of the final concentration) were incubated for each sample. Calculations of bacterial production per $\mathrm{m}^{2}$ and day were made by integrating over depth, assuming homogenous production within the upper and lower parts of the water column and uniform production during the $24 \mathrm{~h}$ of the day. To estimate bacterial respiration, we used information from Van den Meersche et al. (2004), who modelled bacterial uptake of carbon and nitrogen and the corresponding bacterial growth and estimated that approximately $19 \%$ of the carbon uptake goes into production. Assuming that all of the assimilated carbon that is not bound in growth is respired, approximately 4.3 times more carbon is used in respiration than in growth. Using the molar relationship of 12/32 between carbon and oxygen, the conversion factor from bacterial growth in $\mathrm{mg}$ carbon to respiration in $\mathrm{mg}$ oxygen will be $4.3 \times 32 / 12=11.5$.

\section{Results}

Light environment and wall surface

Aluminum-covered walls usually gave the highest irradiance levels at all depths, followed by white walls and then black walls, which absorbed most light (Fig. 2). The wavelength spectrum for the three wall surfaces had a similar shape at all depths (Fig. 2). The white walls reduced the irradiance compared to the aluminumcovered walls, especially between 580 and $700 \mathrm{~nm}$ (Fig. 3a), and in the upper meter of the water parcel, this corresponded to a reduction by 30-70\%. In absolute terms, irradiance differences decreased with depth (Fig. 2a-c), whereas relative differences between both Alu and White and Alu and Black could reach between 200 and $300 \%$ in the region 500-650 $\mathrm{nm}$ in the deeper part of the water column. The difference between White and Black was highly significant in the upper meter of the water parcel, corresponding to a relative difference of 50-100\% higher values for White in the range 450-700 nm. The effect of the different wall surfaces for the irradiance in the entire water parcel was a reduction to $68 \%$ over the entire spectrum with white compared to aluminium walls and a reduction to $46 \%$ with black compared to aluminium walls (Fig. 3d).

\section{Thermal-lid effects}

The 150-W HID metal-halogen lamps produced heat that was transferred to the water, causing an increased temperature that was significant down to $40 \mathrm{~cm}$ in depth (Fig. 4a). A gradual aggregation of organic material on the surface, including bacterial, algae and dead material, takes place as long as the surface is not mixed. Bubbling with ca. 1 bubble s $^{-1}$ at $2 \mathrm{~cm}$ in depth eliminated visible surface aggregation, but the surface water was still heated by the lamp as without bubbling. Both bubbling from $60 \mathrm{~cm}$ in depth (Fig. 4b) and fan blowing (Fig. 4c) eliminated the surface temperature gradient, and the variation in the temperature in the upper meter of the water column was less than $0.3{ }^{\circ} \mathrm{C}$. Convective stirring from the bottom, using a 200-W heater, eliminated most of the temperature increase in the surface layer (Fig. 4d). Without any mixing of the 


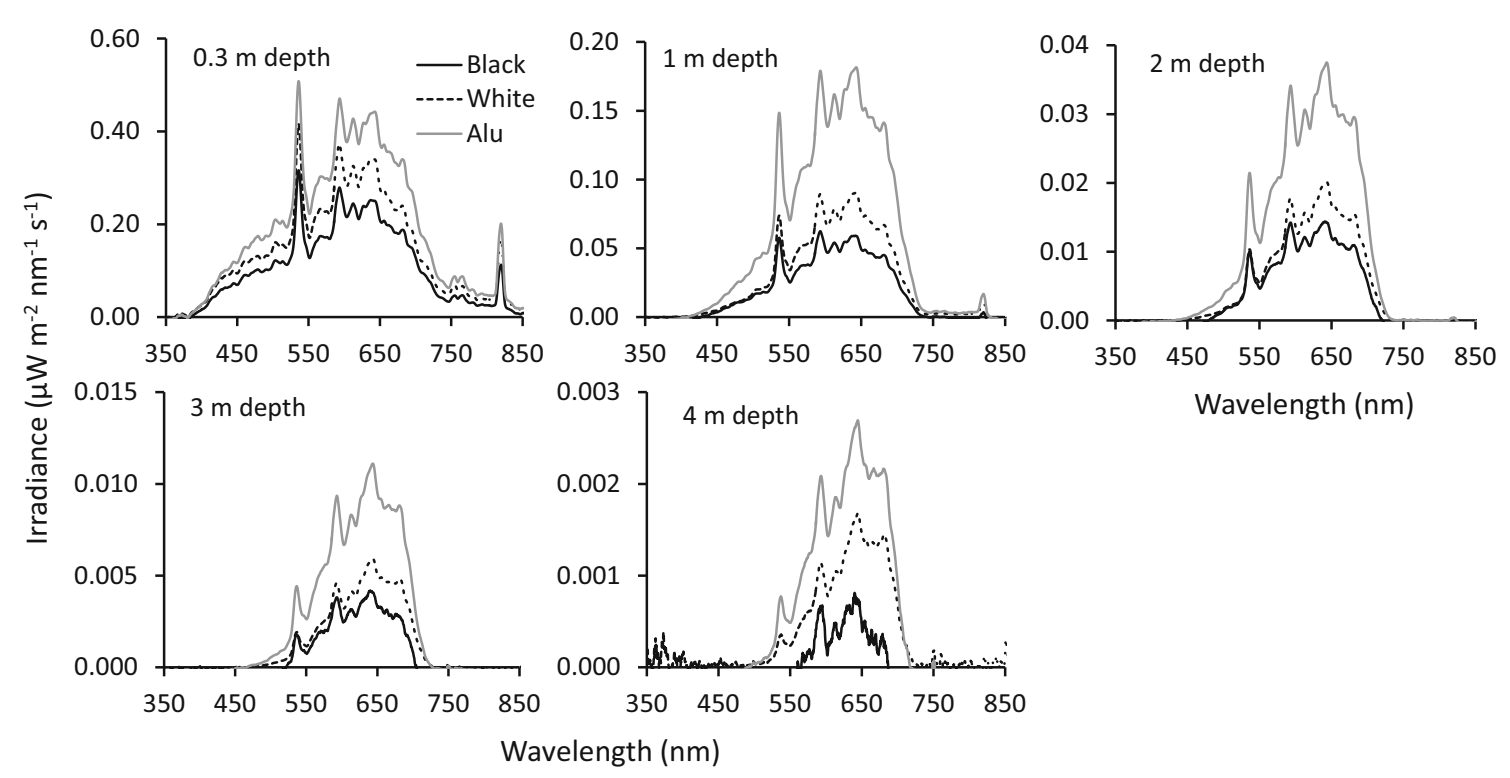

Fig. 2 Absolute irradiance spectrums in mesocosm tanks with three different surfaces on the inside wall and at five different depths. Black is the original polyethene surface. White is a glossy white PVC sheet, and Alu is a tube of aluminium foil kept in place towards the wall by stiff ring-formed plastic tubings
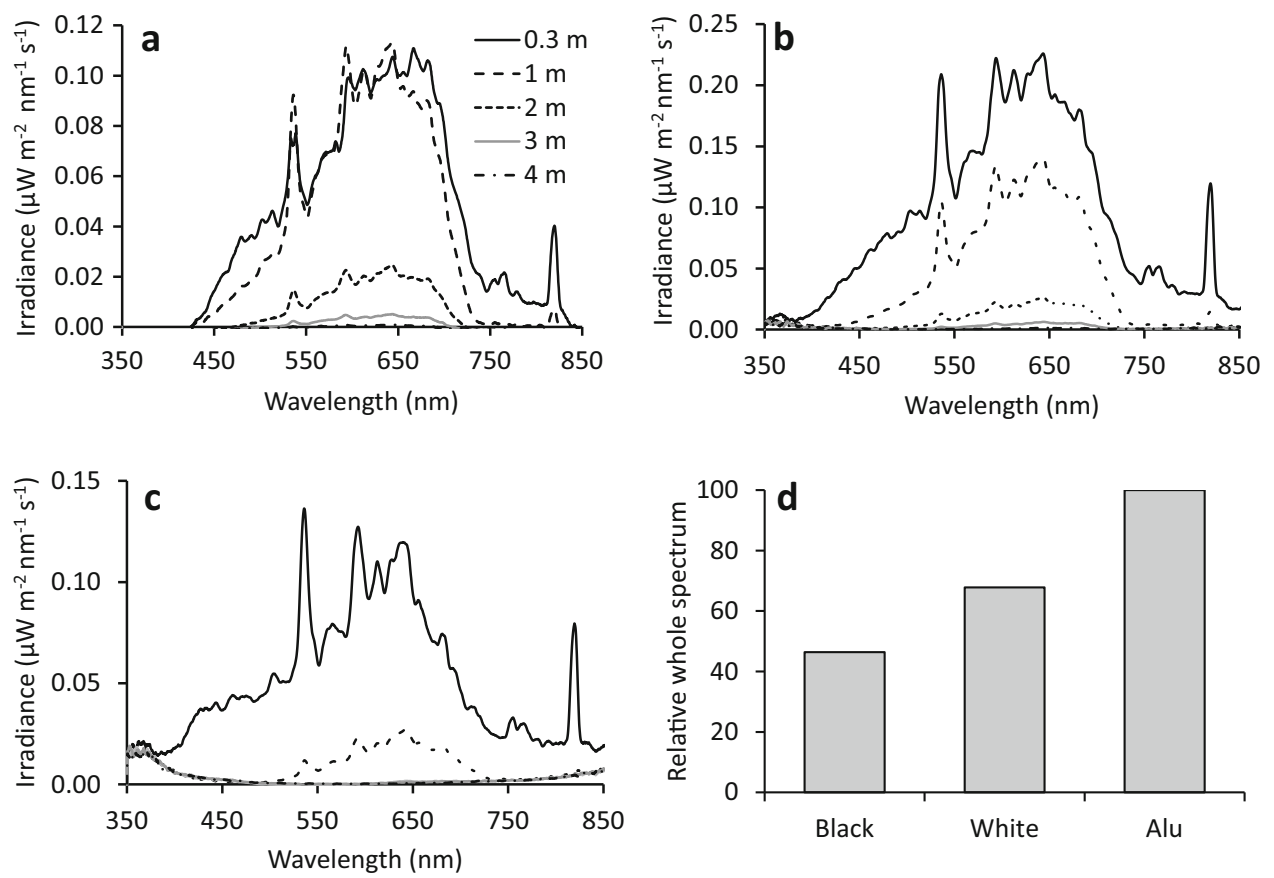

Fig. 3 Differences in absolute irradiance spectrum between mesocosm tanks with three different surfaces on the inside walls. a Alu minus White walls. b Alu minus Black walls. c White minus Black walls. d Relative irradiance values compared to Alu for the entire spectrum $(350-850 \mathrm{~nm})$ and $0-4.4 \mathrm{~m}$ in depth

surface water, as in Fig. 4a, the transport of material up to the surface was slow, and only $60 \%$ of the equilibrium concentration was reached in the upper $10 \mathrm{~cm}$ within $42 \mathrm{~h}$ (Fig. $4 \mathrm{e}$ ). With convective stirring, as in Fig. 4d, the transport up to the surface increased, and the equilibrium concentration in the entire water column was reached within $31 \mathrm{~h}$ (Fig. 4f). 

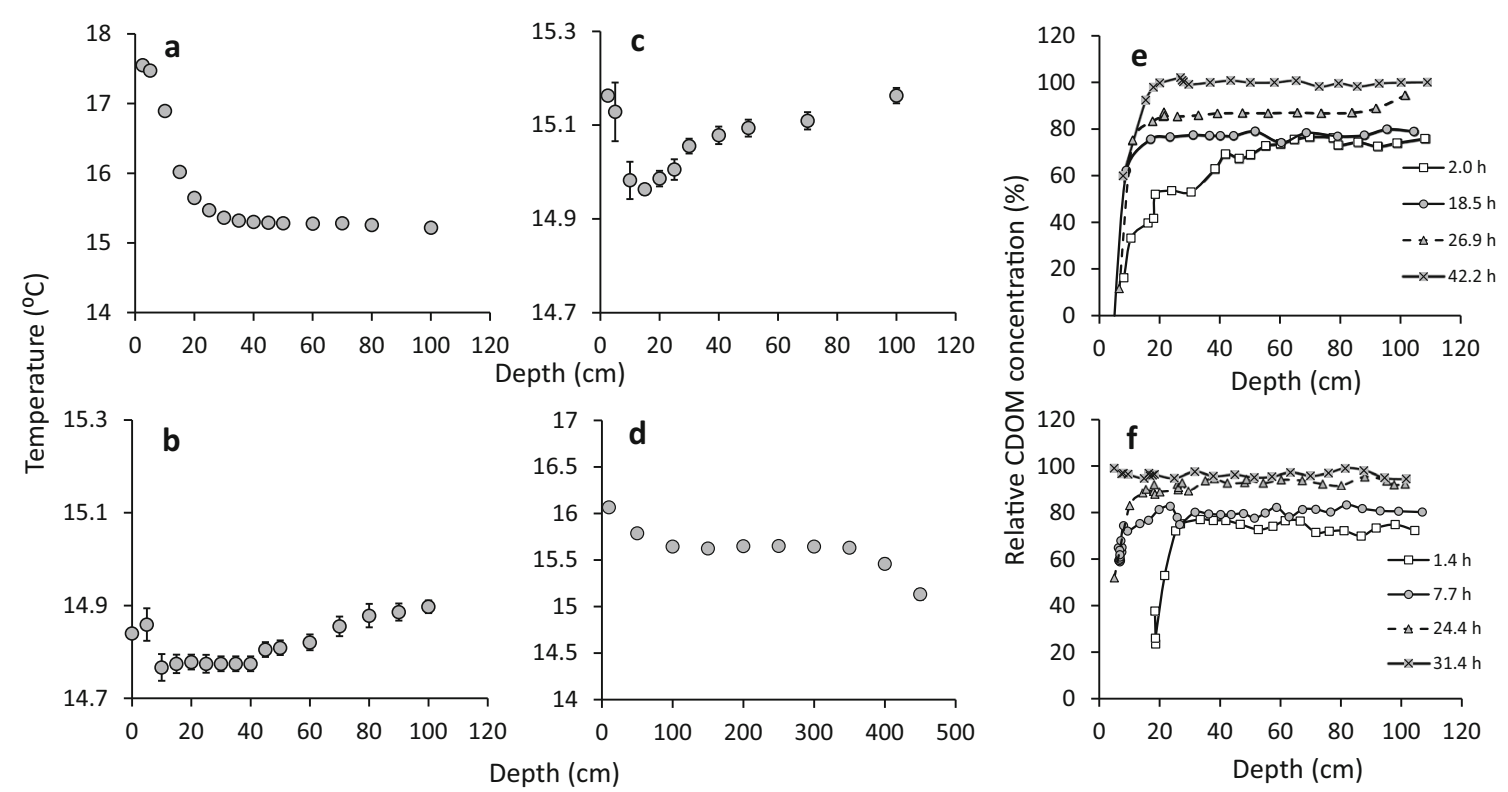

Fig. 4 Temperature profiles (a-d) and transport affected by a thermal lid (e, f) in mesocosms with a 150-W HID metal halogen lamp approximately $50 \mathrm{~cm}$ above the surface, giving an irradiance of ca. $400 \mu \mathrm{mol}$ quanta $\mathrm{m}^{-2} \mathrm{~s}^{-1}$ below the surface. a No mixing in the water column. b Bubbling from $60 \mathrm{~cm}$ in depth. c An undulating fan ( $\pm 45^{\circ}$ side movements) blowing at $45^{\circ}$ on the surface. d A 200-W heater placed close to the bottom of the mesocosm tank. e Succession in relative CDOM concentrations following an injection of humus solution in the middle of the tank and with conditions as in a. $\mathbf{f}$ Succession in relative CDOM concentrations with the conditions in $\mathbf{d}$. Note the different scales on the $Y$-axis in a-d. Vertical lines in a-d denote $95 \%$ confidence intervals, based on 13 measurements along two perpendicular lines of the tank diameter

\section{Transport through thermoclines}

Transport from a stagnant bottom-water layer through thermoclines of 15,10 and $5{ }^{\circ} \mathrm{C}$ temperature gradients was studied while maintaining convective stirring above the thermocline with a $250-\mathrm{W}$ aquarium heater. The temperature profiles differed markedly below $3 \mathrm{~m}$ in depth (Fig. 5a) and generated the observed differences in transport. In the upper $3.3 \mathrm{~m}$ of the water parcel, there was a linear increase in rhodamine concentration, with a rate constant of $0.05,0.08$ and $0.17 \% \mathrm{~h}^{-1}$, respectively, of equilibrium concentration for the temperature gradients 15,10 or $5{ }^{\circ} \mathrm{C}$ at $0.2-1.8 \mathrm{~m}$ and a rate constant of $0.10,0.11$ and $0.24 \% \mathrm{~h}^{-1}$ at $1.8-3.3 \mathrm{~m}$ (Fig. $5 \mathrm{~b}$, $\mathrm{d}, \mathrm{f})$. Within the thermocline, the rhodamine concentration showed a logarithmic increase over time, whereas the bottom layer showed a logarithmic decrease (Fig. 5c, e, g). A plot of transport rate versus the magnitude of the density gradient for the two upper vertical levels showed a relationship best described by a power function (Fig. 6). Transport to the upper layer $(0.2-1.8 \mathrm{~m})$ was slower than to the middle layer $(1.8-3.3 \mathrm{~m})$ and also decreased more with an increase in the density gradient, as shown by the exponent -0.71 compared to -0.52 (Fig. 6). Using the data from 22 to $138 \mathrm{~h}$ for the bottom layer $(3.6-4.7 \mathrm{~m})$ in calculation of the linear regression coefficient gave the data for transport rate versus density gradient for this layer, which showed a similar relationship as the other two layers (Fig. 6).

In an experiment with an upper warmer mixed layer of ca. $1.5 \mathrm{~m}$ in depth, overlaying a stagnant layer with a $5{ }^{\circ} \mathrm{C}$ lower temperature, we used either mixing by bubbling at $60 \mathrm{~cm}$ in depth or fan blowing as a way of getting rid of heat from the lamp. The resulting temperature profiles are displayed in Fig. 7a. The bubbling gave a constant temperature of $15.5^{\circ} \mathrm{C}$ in the upper $1.7 \mathrm{~m}$, a very sharp thermocline, and a constant temperature of $10-11^{\circ} \mathrm{C}$ below the thermocline (Fig. 7a). The fan blowing gave a surface temperature of ca. $14{ }^{\circ} \mathrm{C}$ in the upper $60 \mathrm{~cm}$, thereafter continuously decreasing to a constant temperature of approximately $10{ }^{\circ} \mathrm{C}$ below $230 \mathrm{~cm}$ in depth (Fig. 7a). The rhodamine injected at $240 \mathrm{~cm}$ in depth showed a linear change in concentration over time in the three depth intervals recorded. For the mesocosm with bubbling, the mixing rates at $0-100$ and $100-150 \mathrm{~cm}$ in depth were identical, with an hourly increase in rhodamine concentration of $0.27 \%$ and a decrease below $200 \mathrm{~cm}$ of $0.17 \%$ per hour (Fig. 8b). Fan blowing yielded a faster mixing, with an hourly increase rate of 0.38 and $0.30 \%$ in the two upper layers and a decrease rate below $2 \mathrm{~m}$ in depth of 

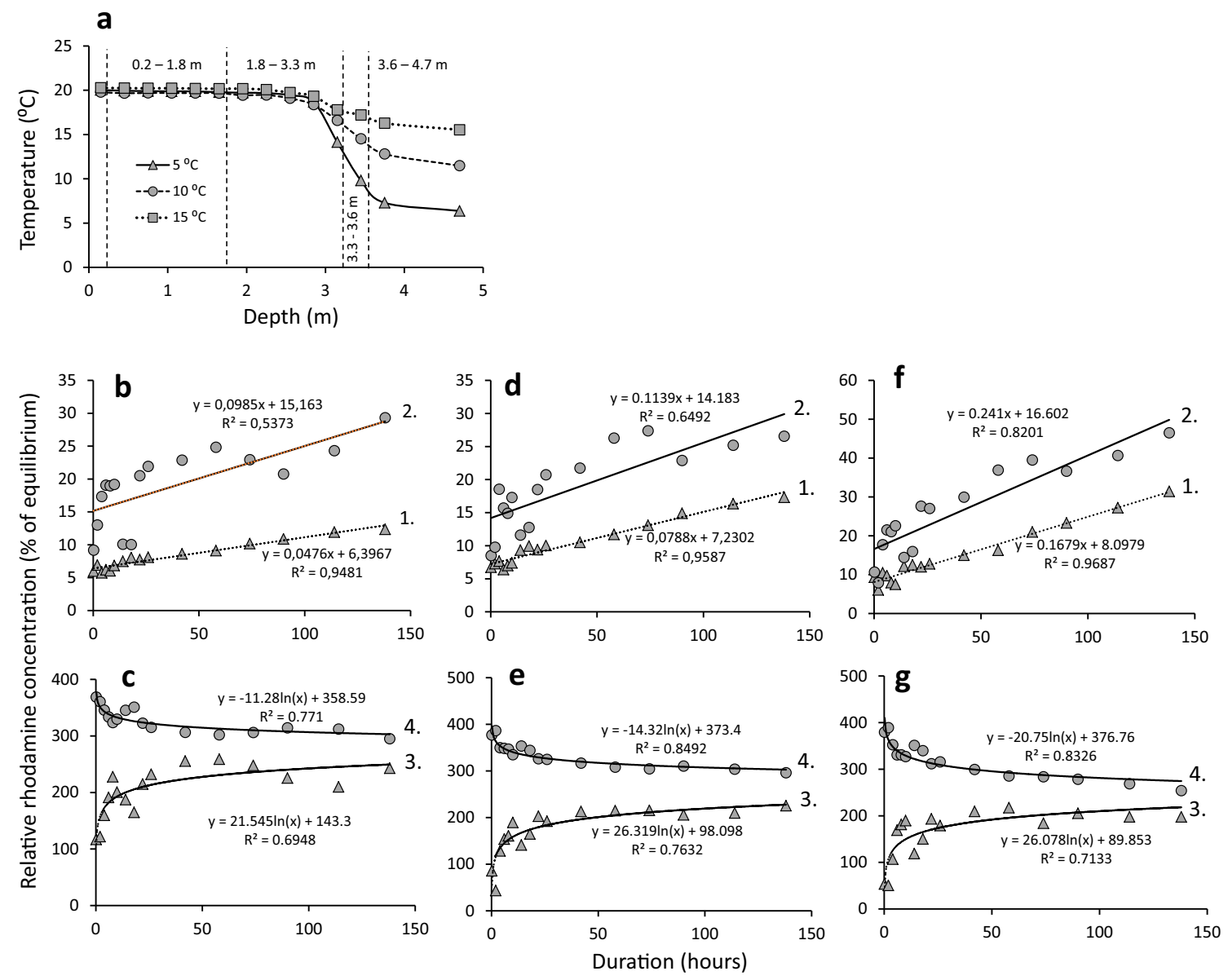

Fig. 5 a Temperature profiles in the studies of transport rates through three different temperature gradients, made by temperature settings in the bottom layer of 5,10 and $15{ }^{\circ} \mathrm{C}$, and $20{ }^{\circ} \mathrm{C}$ above the bottom layer. c-g Succession in relative rhodamine concentration in different vertical levels of the water column. The bottom temperature in $\mathbf{b}$ and $\mathbf{c}$ was $5{ }^{\circ} \mathrm{C}$, in $\mathbf{d}$ and $\mathbf{e}$ was $10{ }^{\circ} \mathrm{C}$, and in $\mathbf{f}$ and $\mathbf{g}$ was $15{ }^{\circ} \mathrm{C}$. The plots represent average values within each of four vertical levels, $0.2-1.8 \mathrm{~m}(1),. 1.8-3.3 \mathrm{~m} \mathrm{(2.)}$, 3.3-3.6 m (3.), and 3.6-4.7 m (4.), and rhodamine was added below the thermocline at the start. Values are given as \% of the equilibrium concentration in layers 1,2 and 3, i.e., the rhodamine concentration if the entire water column was completely mixed. In layer $4,100 \%$ is defined as the starting concentration after the equilibrium concentration has been subtracted. Regression equations best fitting the plots are given in the graphs

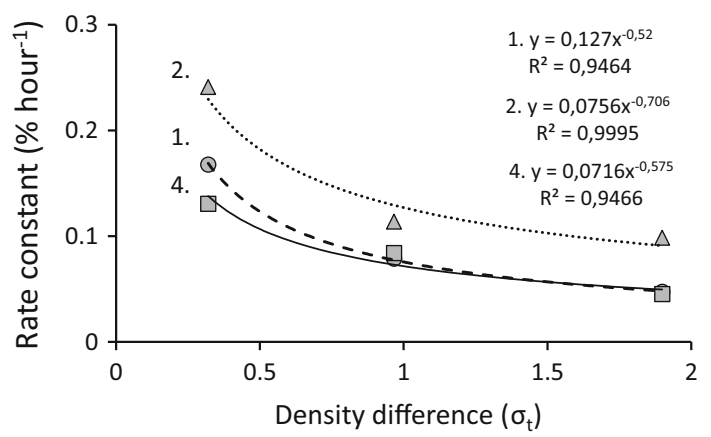

Fig. 6 Transport-rate constant $(Y=\%$ of rhodamine concentration per hour) versus density gradient, i.e., the difference in $\sigma t$ $\left(\mathrm{kg} \mathrm{m}^{-3}\right)$ between the bottom layer and the water parcel above. Data from layers 1, 2 and 4 (see Fig. 5) have been used (for 1 and 2 , with the regression coefficients from the linear regression equations). Regression coefficients based on data for $22-138 \mathrm{~h}$ and linear regression calculations where used for layer 4 . Plots and equations are given that best fit the data 
a

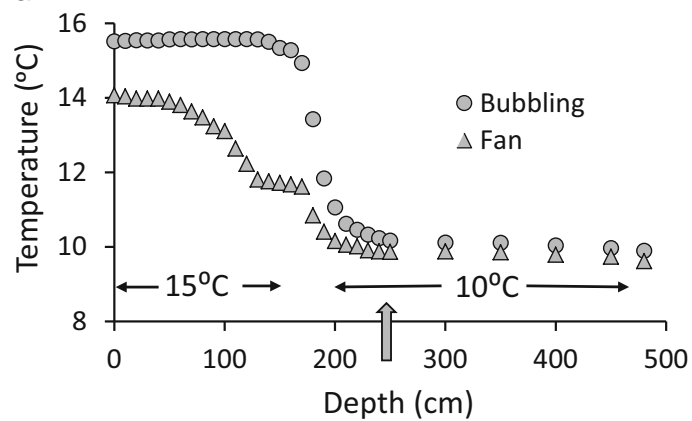

b

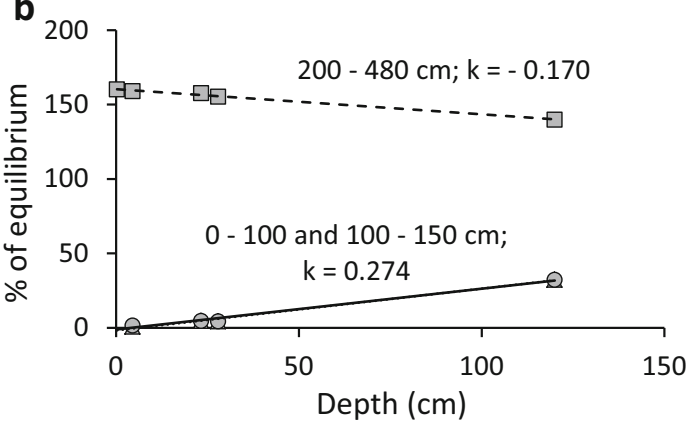

C
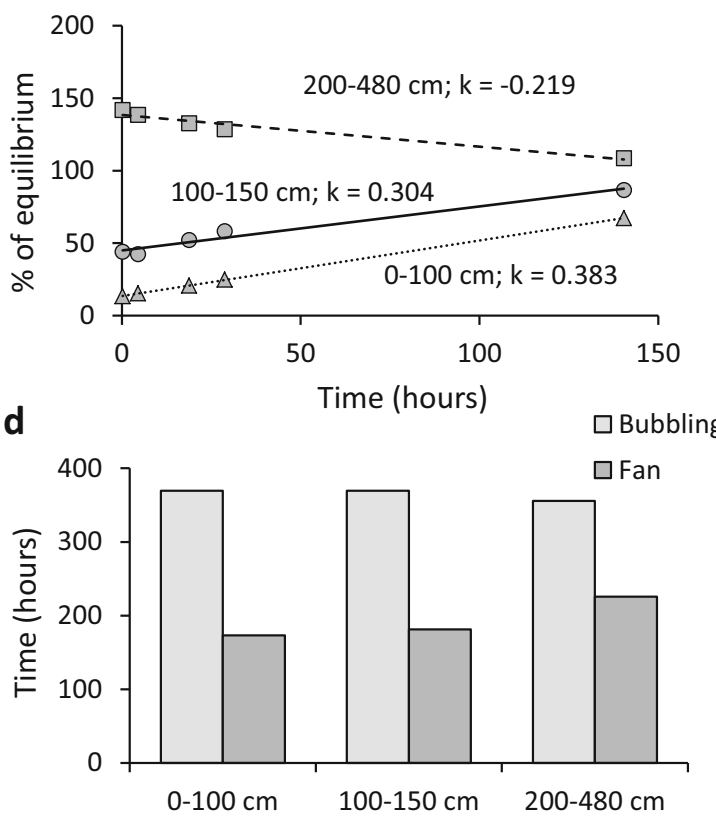

Fig. 7 Temperature profiles with bubble mixing at $60 \mathrm{~cm}$ in depth and fan mixing from the surface. b Mixing rate constant (\% of equilibrium rhodamine distribution) in three different depth intervals and with bubble mixing. c Mixing rate constant with fan mixing. d Time to reach the equilibrium distribution based on linear regression and the estimated mixing-rate constant. Temperature setting as given in the figures. Rhodamine was injected at $2.40 \mathrm{~m}$ in depth (see the arrow in a)

$0.22 \%$ per hour (Fig. 7c). To reach equilibrium concentrations in all three sections, bubble mixing required between 356 and $369 \mathrm{~h}$, whereas the fan treatment required between 173 and $226 \mathrm{~h}$ to reach equilibrium (Fig. 7d).

Non-stratified water mixing

Temperature settings ranging from $16{ }^{\circ} \mathrm{C}$ at the top down to $14{ }^{\circ} \mathrm{C}$ at the bottom gave a gradual decrease of the temperature in the water column from 16.4 at the surface down to $13.9{ }^{\circ} \mathrm{C}$ at $4.5 \mathrm{~m}$ in depth, and with a strong drop further down due to cooling from the bottom (Fig. 8a). There was considerable variation in rhodamine concentrations following injection between the six replicates during the first $36 \mathrm{~h}$ but very uniform levels thereafter, and the equilibrium level was reached after $84 \mathrm{~h}$ (Fig. 8b). With both the temperature control and light switched off, the temperature in the water column was uniform at $16.4{ }^{\circ} \mathrm{C}$ except close to the bottom, where it was $16.2^{\circ} \mathrm{C}$ (Fig. 8c). Equilibrium in rhodamine distribution was reached here within 24 h (Fig. 8d). Maximum convective stirring with the light switched on gave a temperature increase from $40 \mathrm{~cm}$ in depth to the surface of $15.0-16.1^{\circ} \mathrm{C}$, whereas the temperature below $40 \mathrm{~cm}$ in depth varied less than $0.1{ }^{\circ} \mathrm{C}$ from the temperature of $15.0^{\circ} \mathrm{C}$ for the middle section (Fig. 8e). The rhodamine distribution reached equilibrium within $17 \mathrm{~min}$ at $100 \mathrm{~cm}$ in depth and below (Fig. 8f), whereas it took $34 \mathrm{~min}$ to reach equilibrium at $30 \mathrm{~cm}$ in depth and $78 \mathrm{~min}$ at $10 \mathrm{~cm}$ in depth (not shown) as a result of the temperature gradient caused by the lamp above (see also the thermal-lid effects in Fig. 4).

Primary production, turbulence and humus

In our test of the significance of mixing for primary production, we found a dramatic effect when the irradiance in the water parcel was reduced by the addition of humus. The light attenuation coefficient increased from 1.07 to 1.96 and 2.61 for the 4 and $8 \mathrm{mg}^{-1}$ additions, respectively. The primary production based on traditional fixed-depth incubation was successively reduced with added humus. A decrease of more 

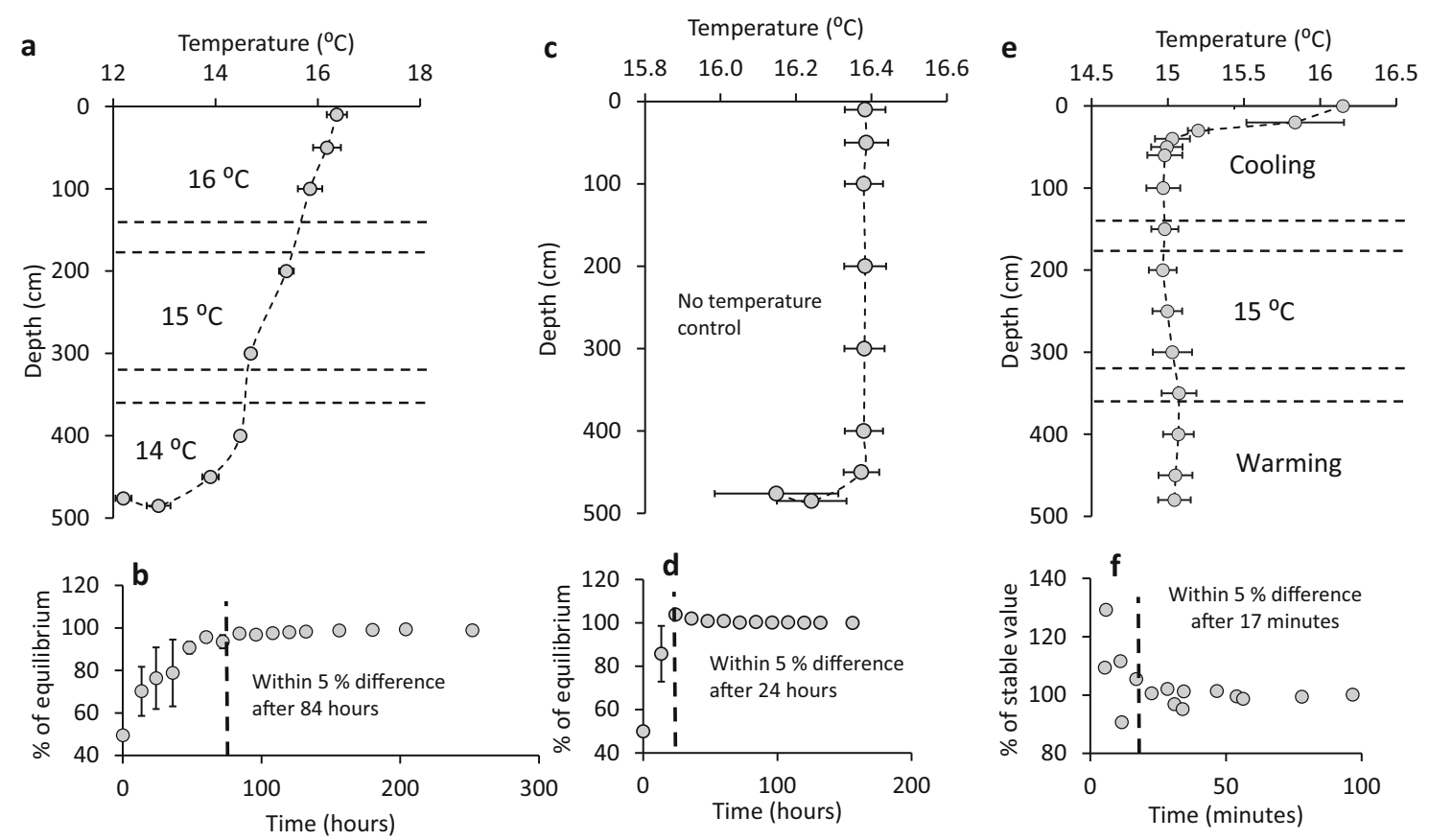

Fig. 8 a Temperature profile with temperature settings of 14,15 and $16{ }^{\circ} \mathrm{C}$ from the bottom up; $\mathbf{b}$ succession of the rhodamine concentration for the condition in a, given as \% of equilibrium; c temperature profile with temperature control switched off. d Succession of the rhodamine concentration for the condition in c, given as $\%$ of equilibrium. e Temperature profile with maximum convective stirring by constant heating the lowest section, maintaining $15{ }^{\circ} \mathrm{C}$ in the middle section and constant cooling in the upper section, and with the lamp above switched on. $\mathbf{f}$ Succession of the rhodamine concentration for the condition in $\mathbf{e}$, given as $\%$ of equilibrium. Vertical lines denote $95 \%$ confidence intervals. Time of complete mixing given in the inserted text in $\mathbf{b}, \mathbf{d}$, and $\mathbf{f}$

than 80 and $60 \%$ for the $8 \mathrm{mg} \mathrm{1^{-1 }}$ additions could be observed for the 0 - to 1.5 - and 0 - to $4.5-\mathrm{m}$ sections, respectively (Fig. 9a). Without any addition, rotation incubation gave a $20 \%$ lower primary production than fixed-depth incubation in the upper $1.5 \mathrm{~m}$ and a $48 \%$ lower production between 0 and $4.5 \mathrm{~m}$ in depth (Fig. 9b). With the addition of $4 \mathrm{mg}$ humus $1^{-1}$, the primary production in rotating incubation corresponded to roughly $300 \%$ of the primary production based on fixed-depth incubation, both for the shallow $(0-1.5 \mathrm{~m})$ and deep $(0-4.5 \mathrm{~m})$ water parcel (Fig. 9b). A further addition of $4 \mathrm{mg}^{-1}$ of humus caused the rotating incubation to reach levels 6.7 times higher in the 0 - to $1.5-\mathrm{m}$ interval and 8.7 times higher in the 0 - to $4.5-\mathrm{m}$ interval compared to fixed-depth incubations (Fig. 9b).

\section{Anoxia through microbial respiration}

The strong pycnocline in this experiment (Fig. 10a) reduced the transport of oxygen to the bottom layer, and the continuous addition of glycol stimulated bacterial production (Fig. 10b). Primary production reached its highest value in day 4 , with $55 \mathrm{mg} \mathrm{C} \mathrm{m}^{-2}$ day $^{-1}$, thereafter ranging between 16 and $42 \mathrm{mg} \mathrm{C} \mathrm{m}^{-2}$ day $^{-1}$ (Fig. 10b), whereas bacterial production increased heavily after day 4 , with the highest value at day 22 , when it was 32 times higher than the primary production (Fig. 10b). The theoretical oxygen consumption by bacterial respiration (see "Materials and methods") increased linearly over time with all oxygen respired for the upper water layer $\left(18{ }^{\circ} \mathrm{C}\right)$ within 20 days and for the bottom layer $\left(10^{\circ} \mathrm{C}\right)$ within 23 days, assuming no oxygenation of the water (Fig. 10c). The actual measured oxygen level in the bottom layer had reached down to a $2 \%$ saturation level at day 19 (Fig. 10d). Although the water above the pycnocline was mixed by an air-lift system (see "Materials and methods"), the oxygen saturation level was also reduced here, from over 130\% in the beginning to between 58 and $81 \%$ after day 15 (Fig. 10d). 
a
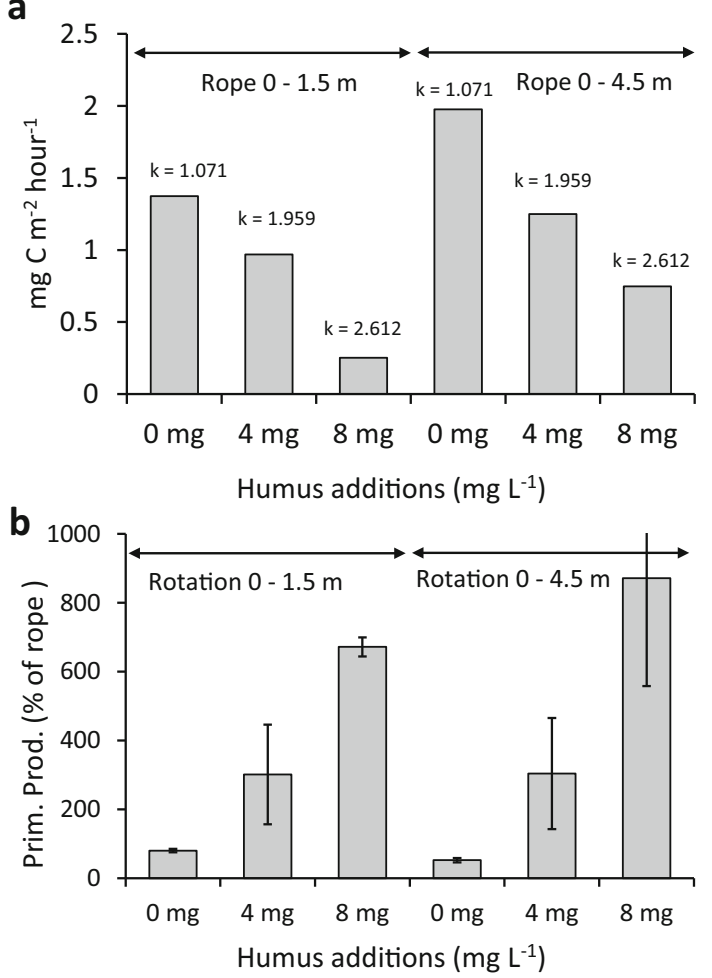

Fig. 9 Primary production based on rope incubations at five depths (a) and primary production using rotating incubations, either between the surface and $1.5 \mathrm{~m}$ in depth or down to $4.5 \mathrm{~m}$ in depth, expressed as relative production compared to rope incubation (b). Rope and rotating incubations were made simultaneously and at three different occasions with different humus content: no humus addition, 4 and $8 \mathrm{mg}^{-1}$. Rotating speed $=97 \mathrm{~cm} \mathrm{~min}^{-1}$. Vertical lines in $\mathbf{b}$ denote $95 \%$ confidence intervals

\section{Discussion}

Ecological studies where mesocosms are used to simulate natural conditions usually do not include measurements that describe all physical conditions of importance for the succession in the ecosystem. Irradiance as PAR (400-700 $\mathrm{nm}$ in wavelength), salinity and temperature are commonly included variables, whereas spectral distribution and level of turbulent mixing are seldom measured. The ultra-violet radiation from sunlight is known to affect microorganisms and especially bacteria negatively, but Ogbebo and Ochs (2008) showed that this effect was significant only with added inorganic nutrients, and then with a stronger effect on phytoplankton production (45\% reduction) compared to bacterioplankton production (21\% reduction). In addition, sunlight also causes photolysis of DOC (dissolved organic carbon), which will transform carbon compounds and make them more bioavailable for bacterioplankton (Bertilsson et al. 1999; Tranvik and Bertilsson 2001). Such effects of sunlight will, therefore, have a strong impact on the overall production, as well as the trophic balance of the system. By mesocosm enclosures with different types of inside material and different light sources, both quantity (PAR irradiance) and quality (spectral distribution) of the light climate in the water column can be manipulated, as shown in our Figs. 2 and 3.

One feature of solid mesocosm tanks is that the tank walls do not let light in from the sides into the water column. This is in contrast to in situ mesocosms, which are usually made of a thin plastic material, although of variable opacity. The light penetrating the water column is absorbed by the water itself, as well as by dissolved and particulate material. Light hitting the wall of a solid tank is partly absorbed and partly reflected, with the relative proportion dependent on the surface material and also how clean the surface is. One important factor for indoor mesocosms is the light source, where the beam angle is a key factor. In nature, the light beam from the sun is essentially parallel, while an electric light source over a mesocosm tank delivers a diverging light beam. The wider the beam angle from the light source, the higher the attenuation through absorption on the wall. In our mesocosm experiments, we recorded light attenuation coefficients ranging from 0.521 (pure tap 

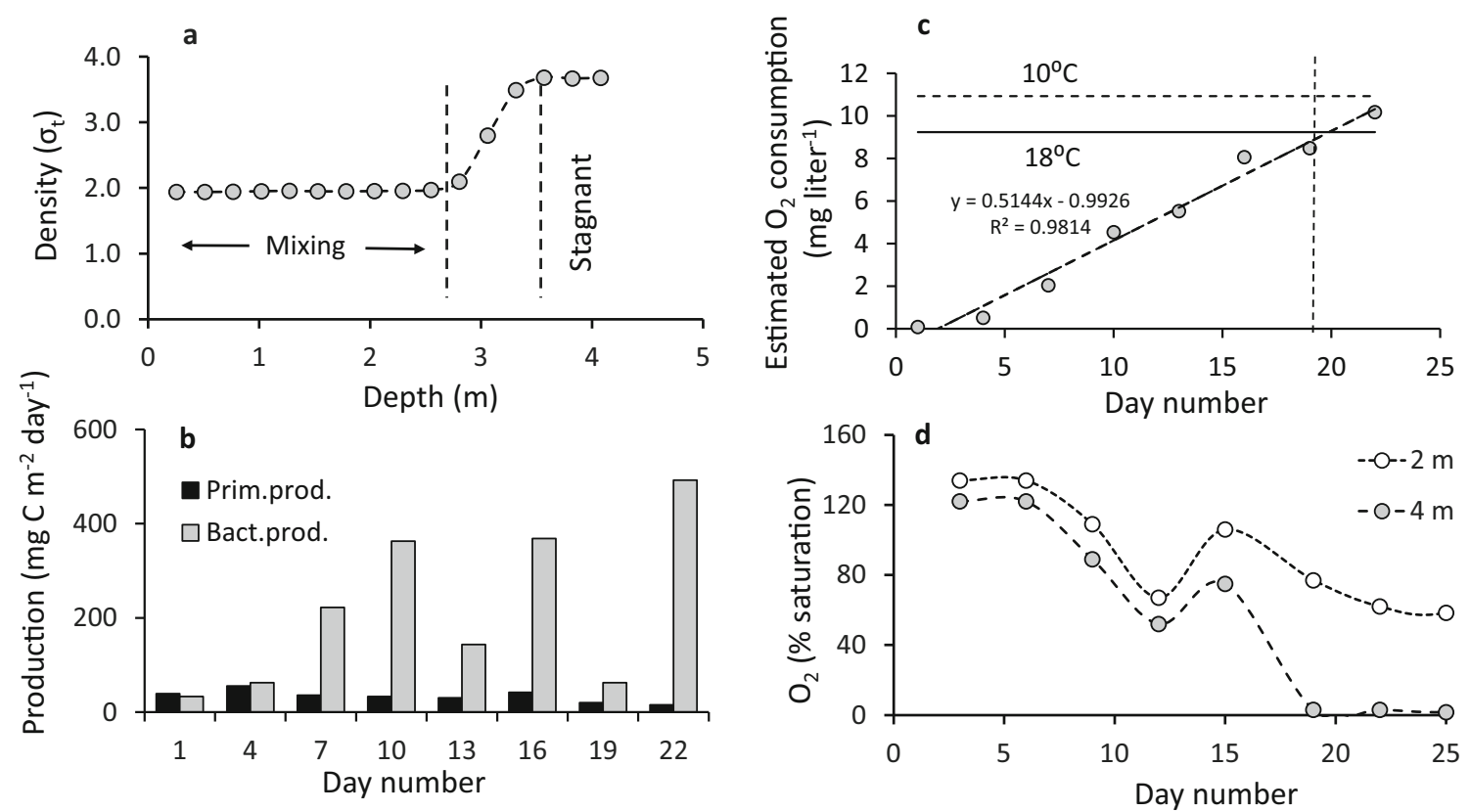

Fig. 10 Experiment forcing anoxic conditions in the bottom water through changes in microbial production balance. Glycol as an organic carbon source was used to stimulate bacterial production. a Vertical profile of density. b Succession in primary production and bacterial production. c Estimated succession in oxygen consumption through bacterial respiration without water exchange through the pycnocline. d Succession in oxygen saturation level in the water above the stagnant bottom water ( $2 \mathrm{~m}$ in depth) and within the stagnant bottom water ( $4 \mathrm{~m}$ in depth). Airlift mixing (see "Materials and methods") from $3.5 \mathrm{~m}$ in depth explains the oversaturation of oxygen during part of the experiment. The two horizontal lines in $\mathbf{c}$ denote the level of saturated oxygen content above $\left(18{ }^{\circ} \mathrm{C}\right)$ and below $\left(10^{\circ} \mathrm{C}\right)$ the pycnocline

water) up to 2.612 [natural water with a high allochthonous dissolved organic carbon (ADOC) content], which can be compared to coefficients measured in the northern Bothnian Sea between June and December, where the average coefficient was 0.595 , ranging from 0.300 up to 1.425 (own unpublished data). The negative consequence of a higher-than-natural light attenuation coefficient is that the same light-depth relationship as in nature cannot be reproduced. However, at the same time, it might be an advantage, since the irradiance profile in a natural water column can be reproduced on a compressed depth scale. For example, in the experiment by Båmstedt and Wikner (2016), the average compensation depth was $3.2 \mathrm{~m}$ without added ADOC and $2.6 \mathrm{~m}$ with added ADOC, whereas field measurements gave a range from 3.2 to $15.4 \mathrm{~m}$, with an average of $7.7 \mathrm{~m}$.

Pycnocline strength and turbulent mixing are physical properties that are of the utmost importance in, for example, supplying nutrients from deeper water to the euphotic zone or supplying oxygen from above to benthic organisms. The effect of variable pycnocline strength and turbulent mixing on ecosystem components can easily be studied in mesocosm experiments, but mesocosms of the type we describe here are also suitable tools for direct physical studies of how different combinations of pycnocline strength and turbulent mixing govern transport rates, as exemplified in our Figs. 5 and 6.

When using mesocosms to simulate a natural ecosystem, one major challenge is to create mixing, since the natural mechanisms of mixing will be altered in a closed water parcel. In our study, we found that mixing in the uppermost few $\mathrm{cm}$ of the water parcel is necessary to eliminate a gradually increasing surface aggregation of organic material. Mixing from $60 \mathrm{~cm}$ in depth was also necessary with our illumination system to eliminate the thermal-lid effect caused by heat from the lamps. The exchange of material between the surface and deeper layers is clearly hampered by the existence of a surface section that is warmer than the water below (Fig. 4e, f). The combination of a low mixing rate in the water column and temperature stratification at the surface may influence the exchange of gases between the water column and the atmosphere and the transport of nutrients from deeper water to the surface layer. In the worst case, this can lead to mesocosm environments that differ significantly from the prevailing natural conditions. Because different lamps produce different amounts of heat, it is necessary to investigate the actual condition for each mesocosm facility. Both bubbling with air from 
$60 \mathrm{~cm}$ in depth and blowing air on the surface with a fan eliminated thermal stratification at the surface (Fig. 4b, c). The use of a fan, however, caused a significantly higher loss of water due to evaporation and a lower surface temperature as compared to bubbling (Fig. 7a). The explanation for this effect is as follows: the enthalpy of water evaporation is $2260 \mathrm{~kJ}$ per $\mathrm{kg}$ (see textbooks on thermodynamics), and this energy is taken from the water, thereby causing a cooling of the surface layer and a different temperature profile as compared to air bubbling. The logic of the difference in temperature profile is a difference in transport rate, clearly illustrated in our Fig. 7d. The results are a strong reminder that the same methods should always be used if the results from different experiments are to be compared.

Striebel et al. (2013) compared the effect of three methods of mesocosm mixing, following a plankton community over 19 days and using a disc that moves up and down, an air-lift system and air bubbling. Mechanical mixing with the disc generated the highest zooplankton biomass, and an air-lift system generated a lower proportion of small flagellates, but otherwise, all methods gave the same community composition of phytoplankton and zooplankton. From mesocosm studies in Lake Thaihu, Zhou et al. (2016a) showed that the turbulence level had a strong impact on the structure of the zooplankton community, with a shift from the dominance of large-sized crustaceans to small-sized rotifers with increased turbulence. High turbulence also suppressed the zooplankton growth and biomass. Zou et al. (2016b) also reported a strong positive influence of turbulent mixing on the production of autochthonous chromophoric dissolved organic matter (CDOM). We have mainly used convective stirring as a standard method of mixing, since it corresponds better to field conditions than mixing by pumps, propellers or air bubbles (e.g., Paul et al. 2012; Sjöqvist et al. 2014). This is done either by slightly different temperature settings for the temperature-control mantles, or by submerging an electrical heater, or by both. The maximum convective stirring settings correspond to only 17 min for complete mixing of the mesocosm water (Fig. 8f) with still a rather uniform temperature profile (Fig. 8e). These results show that high stirring rates can be achieved and that the overall temperature is precisely controlled by the setting of the middle section under these circumstances. The range in mixing rate, exemplified in Fig. 8, with relatively small differences in temperature profiles, shows that mixing by convective stirring is a versatile and effective method of creating different turbulent environments. However, to achieve a given mixing rate for a certain type of mesocosm, calibration measurements are necessary. We have used rhodamine injections for this purpose, with the criterion that mixing is achieved when the concentration of rhodamine has stabilized to within $95-105 \%$ of the equilibrium value.

Our results of primary production from rotating incubations (Fig. 9) also indicate a dramatic importance of turbulent mixing in water with a high content of humus, which causes brownification of the water, with an increased production ratio between rotation/fixed-point incubations with increased humus. Because primary production with a radioactive tracer technique is measured either by in situ incubations at fixed depths or in an incubator with a series of fixed light levels, such an effect from turbulent mixing will not be accounted for. Almost 40 years ago, Marra (1978) noted that variation in incubation depth yielded higher primary production than incubations at fixed depths. In addition, Gieskes et al. (1979) noted from their studies in the tropical open ocean that the primary production in the upper part of the euphotic zone was underestimated, probably caused by more rapid bleaching of chlorophyll in algal cells incubated at fixed depths compared to cells freely circulating in the vertically mixed surface layer. This important topic obviously needs more attention. If further studies show this issue to be of general significance, future measurements of the primary production in situ and in incubators should be made in better accordance with the prevailing turbulent mixing conditions.

Turbulent mixing is also of profound importance for the diffusive boundary layer above the bottom sediment and for the transportation of material and properties through a pycnocline, such as supplying the photic zone with nutrients from the deeper layers and for oxygen-rich surface water to reach the deeper layers. Lucas et al. (2016) used an oscillating grid mesocosm in which the turbulence could be varied and found that the thickness of the oxygen-diffusive boundary layer was inversely related and that the oxygen penetration depth in different sediments was positively related to the turbulence intensity. Our study on oxygen depletion in the bottom layer (Fig. 10) showed the effect of enrichment of bioavailable DOC for the oxygen concentration in the bottom layer. However, the estimated theoretical consumption of oxygen through bacterial respiration indicated that 23 days would be required for the observed reduction (Fig. 10c). The density difference between the upper and lower water layer was $1.737 \mathrm{~g} \mathrm{~kg}^{-1}$, and if we use Eq. 4 in Fig. 7, we see that the transport rate from the bottom layer would be $0.053 \%$ per hour. This means that $1.27 \%$ per day of the bottom water is replaced by more oxygenated water from above, which would then somewhat reduce the 
effect of bacterial respiration. Bacterial abundance in the mesocosm with glycol addition was 35-66\% higher than mesocosms without glycol addition, and bacterial production was between 150 and $168 \%$ higher (data not shown), clearly showing the stimulating effect of glycol on the bacterial community. We can only speculate about the difference between the theoretical and observed oxygen succession, and one aspect may be a lower theoretical growth efficiency than the $19 \%$ we used (see "Materials and methods"). The fact that the bacterial production increased by $150-168 \%$ with glycol but the bacterial abundance only increased by $35-66 \%$ might indicate that glycol was mainly used for respiration. Higher-resolution measurements, both in time and depth, would probably also provide a better basis for explanation. Here, our primary goal was to show that an anoxic environment can be achieved in a mesocosm enclosure via natural biological processes.

\section{Final remark}

We have described a unique aquatic mesocosm facility that is highly versatile regarding physical conditions in the water column. Such an experimental tool is of utmost importance in simulating environmental changes like, e.g., the ongoing climate change, and for studying the effects on the ecosystem. Ignoring factors like turbulent mixing, density stratification and light spectrum might give results that diverge from the natural environment and which thereby support wrong environmental management decisions.

Acknowledgements The work was conducted with support from the Nordic Marine Academy, the European Union Seventh Framework Program (FP7/2007-2013) under Grant agreement no. 228224, (MESOAQUA), and the Strategic Marine Environmental Research program Ecosystem dynamics in the Baltic Sea in a changing climate perspective (ECOCHANGE). We thank Umeå marine sciences centre for good working facilities and necessary technical support during all parts of the study.

Open Access This article is distributed under the terms of the Creative Commons Attribution 4.0 International License (http:// creativecommons.org/licenses/by/4.0/), which permits unrestricted use, distribution, and reproduction in any medium, provided you give appropriate credit to the original author(s) and the source, provide a link to the Creative Commons license, and indicate if changes were made.

\section{References}

Aminot A, Rey F (2002) Chlorophyll a: determination by spectroscopic methods. ICES Tech Mar Environ Sci 30:1-18

Båmstedt U, Wikner J (2016) Mixing depth and allochthonous dissolved organic carbon: controlling factors of coastal trophic balance. Mar Ecol Prog Ser 561:17-29

Bertilsson S, Stepanauskas R, Cuadros-Hansson R, Graneli W, Wikner J, Tranvik L (1999) Photochemically induced changes in bioavailable carbon and nitrogen pools in a boreal watershed. Aquat Microb Ecol 19:47-56

Caquet T, Lagadic L, Monod G, Lacaze JC, Coute A (2001) Variability of physicochemical and biological parameters between replicated outdoor freshwater lentic mesocosms. Ecotoxicology 10:51-66

Colijn F, Edler L (eds) (1998) Working manual and supporting papers on the use of a standardised incubator-technique in primary production measurements. In: Report of the working group on phytoplankton ecology. CM 1998/C: 3. ICES, Copenhagen, pp 49-57

Dzialowski AR, Rzepecki M, Kostrzewska-Szlakowska I, Kalinowska K, Palash A, Lennon JT (2014) Are the abiotic and biotic characteristics of aquatic mesocosms representative of in situ conditions? J Limnol 73:603-612

Gieskes WWC, Kraay GW, Baars MA (1979) Current C-14 methods for measuring primary production—gross underestimates in oceanic waters. Neth J Sea Res 13:58-78

Jonsson S, Skyllberg U, Nilsson MB, Lundberg E, Andersson A, Björn E (2014) Differentiated availability of geochemical mercury pools controls methylmercury levels in estuarine sediment and biota. Nat Commun 5:10

Lucas S, Moulin F, Guizien K (2016) Oscillating grid mesocosm for studying oxygen dynamics under controlled unsteady turbulence. Limnol Oceanogr Methods 14:1-13

Marra J (1978) Phytoplankton photosyntthetic response to vertical movement in a mixed layer. Mar Biol 46:203-208

Miko Z, Ujszegi J, Gal Z, Imrei Z, Hettyey A (2015) Choice of experimental venue matters in ecotoxicology studies: comparison of a laboratory-based and an outdoor mesocosm experiment. Aquat Toxicol 167:20-30

Ogbebo FE, Ochs C (2008) Bacterioplankton and phytoplankton production rates compared at different levels of solar ultraviolet radiation and limiting nutrient ratios. J Plankton Res 30:1271-1284

Paul C, Reunamo A, Lindehoff E, Bergkvist J, Mausz MA, Larsson H, Richter H, Wängberg SÅ, Leskinen P, Båmstedt U, Pohnert G (2012) Diatom derived polyunsaturated aldehydes do not structure the planktonic microbial community in a mesocosm study. Mar Drugs 10:775-792

Petersen JE, Englund G (2005) Dimensional approaches to designing better experimental ecosystems: a practitioners guide with examples. Oecologia 145:216-224 
Petersen JE, Cornwell JC, Kemp WM (1999) Implicit scaling in the design of experimental aquatic ecosystems. Oikos 85:3-18

Schindler DW (1998) Replication versus realism: the need for ecosystem-scale experiments. Ecosystems 1:323-334

Sjöqvist C, Kremp A, Lindehoff E, Båmstedt U, Egardt J, Gross S, Jönsson M, Larsson H, Pohnert G, Richter H, Selander E, Godhe A (2014) Effects of grazer presence on genetic structure of a phenotypically diverse diatom population. Microb Ecol 67:83-95

Spivak AC, Vanni MJ, Mette EM (2011) Moving on up: can results from simple aquatic mesocosm experiments be applied across broad spatial scales? Freshw Biol 56:279-291

Stewart RIA, Dossena M, Bohan DA, Jeppesen E, Kordas RL, Ledger ME, Meerhoff M, Moss B, Mulder C, Shurin JB, Suttle B, Thompson R, Trimmer M, Woodward G (2013) Mesocosm experiments as a tool for ecological climate-change research. Adv Ecol Res 48(Global Change in Multispecies Systems, Pt 3):71-181

Striebel M, Kirchmaier L, Hingsamer P (2013) Different mixing techniques in experimental mesocosms-does mixing affect plankton biomass and community composition? Limnol Oceanogr Methods 11:176-186

Tranvik LJ, Bertilsson S (2001) Contrasting effects of solar UV radiation on dissolved organic sources for bacterial growth. Ecol Lett 4:458-463

Van den Meersche K, Middelburg JJ, Soetaert K, van Rijswijk P, Boschker HTS, Heip CHR (2004) Carbon-nitrogen coupling and algal-bacterial interactions during an experimental bloom: modelling a C-13 tracer experiment. Limnol Oceanogr 49:862-878

Wikner J, Hagström $\AA$ (1999) Bacterioplankton intra-annual variability: importance of hydrography and competition. Aquat Microb Ecol 20:245-260

Williams P, Whitfield M, Biggs J, Fox G, Nicolet P, Shillabeer N, Sherratt T, Heneghan P, Jepson P, Maund S (2002) How realistic are outdoor microcosms? A comparison of the biota of microcosms and natural ponds. Environ Toxicol Chem $21: 143-150$

Zhou J, Han XX, Qin BQ, Casenave C, Yang GJ (2016a) Response of zooplankton community to turbulence in large, shallow Lake Taihu: a mesocosm experiment. Fundam Appl Limnol 187:315-324

Zhou YQ, Zhou J, Jeppesen E, Zhang Y, Qin B, Shi K, Tang X, Han X (2016b) Will enhanced turbulence in inland waters result in elevated production of autochthonous dissolved organic matter? Sci Total Environ 543:405-415

\section{Publisher's Note}

Springer Nature remains neutral with regard to jurisdictional claims in published maps and institutional affiliations. 